\title{
Safe use of vascular stapling devices during laparoscopic cholecystectomy in cases with enlarged cystic canal
}

\author{
Yurdakul Deniz Firat $\odot$, Mehmet Fatih Erol $\odot$
}

Department of General Surgery, University of Health Sciences, Bursa Yüksek Ihtisas Training and Research Hospital, Bursa, Turkey

\begin{abstract}
Objectives: Bile duct injuries and fistulas due to bile leakage are observed at certain rates in laparoscopic cholecystectomy. In complicated cases, in patients with cholelithiasis cystic duct edema, the cystic canal may be enlarged to the extent that it cannot be closed with a clip in a standard operation. In this study we evaluated the eficiency of stapler closure of cystic canal.

Methods: In this retrospective study the cases who had laparoscopic cholecystectomy and cystic canal was closed with stapler between August 2016 and December 2018 were reviewed. Patients' hospital stay and complications were noted.

Results: Thirty-three patients who were electively operated and cystic canal closure was performed with vascular staples because of a wide cystic canal during the operation were included in this study. Low bile drainage was observed in only one case and this patient had spontaneous regression with conservative followup. Mean duration of hospital stay was 3.7 days. Patients were followed up from 2 months to 28 months postoperatively.

Conclusions: Endo-vasculer stapler can be used safely during laparoscopic cholecystectomy with a history of stones in the main bile duct. In this group of patients, it is advisable to make preparations in this direction before the operation.

Keywords: Wide cystic, endostapler, laparoscopic cholecystectomy, cholelithiasis
\end{abstract}

T he gold standard surgical treatment for cholelithiasis is now laparoscopiccholecystectomy [1]. The cholelithiasis operation can be recommended prophylactically in asymptomatic patients because of the risk of developing cancer, causing biliary pancreatitis, and the complications of long life expectancy.

Acute cholecystitis, chronic cholecystitis, biliary pancreatitis, biliary colic, stone in the main bile duct, cholangitis, Mirizzi syndrome, gallstone ileus and gallbladder cancer may arise from cholelithiasis or might be the complications of gallbladder stones and laparoscopic cholecystectomy should be performed under appropriate conditions [2, 3]. During laparoscopic cholecystectomy, there are technical difficulties that can make operations hard. Some of the technical difficulties include embedded gallbladder, short and thick cystic duct, anatomical anomalies, Mirizzi syndrome, fibrosis in the Calot triangle (frozen calot), empyema, gallbladder edema and inflammation secondary to intraabdominal adhesions [4].

The encountered situations might change the 
course of the operation and may require interventions, including transforming the conversion to open, $\mathrm{T}$ tube application into choledochus, percutaneous transhepatic bile drainage, tube duodenostomy, choledochoduodenostomy, hepaticojejunostomy and other interventions to decrease mortality and morbidity.

The cystic canal is sometimes edematous and the fibrous structure is thickened, or due to the expansion of the lumen, management of the operation becomes complicated. Various techniques in the literature for ligation of cystic channels include intra-corporal knots, titanium clips, endo-loop use and endo-stapler.

In this study, data were collected from 33 patients that, Endo-vasculer stapler were used for enlarged cystic canal ligation, during elective laparoscopic cholecystectomy.

\section{METHODS}

Of the 2573 laparoscopic cholecystectomy cases performed between August 2016 and December 2018, 441 cases were accepted as complicated (choledocholithiasis, acute biliary pancreatitis, acute cholecystitis, acute cholangitis, etc.).

Emergency laparoscopic cholecystectomy was performed in 47 patients for acute cholecystitis, and laparoscopic conversion to open surgery was performed in 16 patients. Four patients were treated with the endo-vasculer stapler because of acute cholecystitis due to a wide cystic duct. Fourteen patients underwent elective laparoscopic cholecystectomy conversion to open surgery.

The number of elective cases with wide cystic channels that Endo-vasculer stapler was used was 33. Our choice of stapler for cystic canal closure was the Endo-GIA $45 \mathrm{~mm}-2.5 \mathrm{~mm}$ with vascular (white) stapler. (Medtronic California USA).

Patient files were retrospectively obtained. Age, gender, preoperative diagnosis, additional pathologies, morbidity and treatment management, length of hospital stay and physical examination findings, imaging findings, operation notes, epicrisis and ERCP datas were recorded.

Within 33 patients, 14 had previous ERCP and stone extraction in their history. Complicated cases were consulted to the hepatobiliary surgeon peroperatively, before the decision of using the Endovasculer stapler. After agreeing on the biliary anatomy,the stapler indication was planned.

Operations were performed with 4 trocar techniques under general anesthesia. Following posterior dissection, Calot Triangle dissection was revealed by leaving cystic artery and cystic duct seperate. When the cystic canal diameter was not enough to be safely closed with titanium ML or Large and with a Polymer Large, XLclip that was the case in the patients with channel above one centimeter, the operations and the cystic stump's safety was questionable. That's why a vascular white 45 Endo-GIATM stapler was used in these patients.

After inspecting and manually controlling the cystic duct, and endovascular stapler was loaded with a white cartiridge and fired in being sure of no sxtones

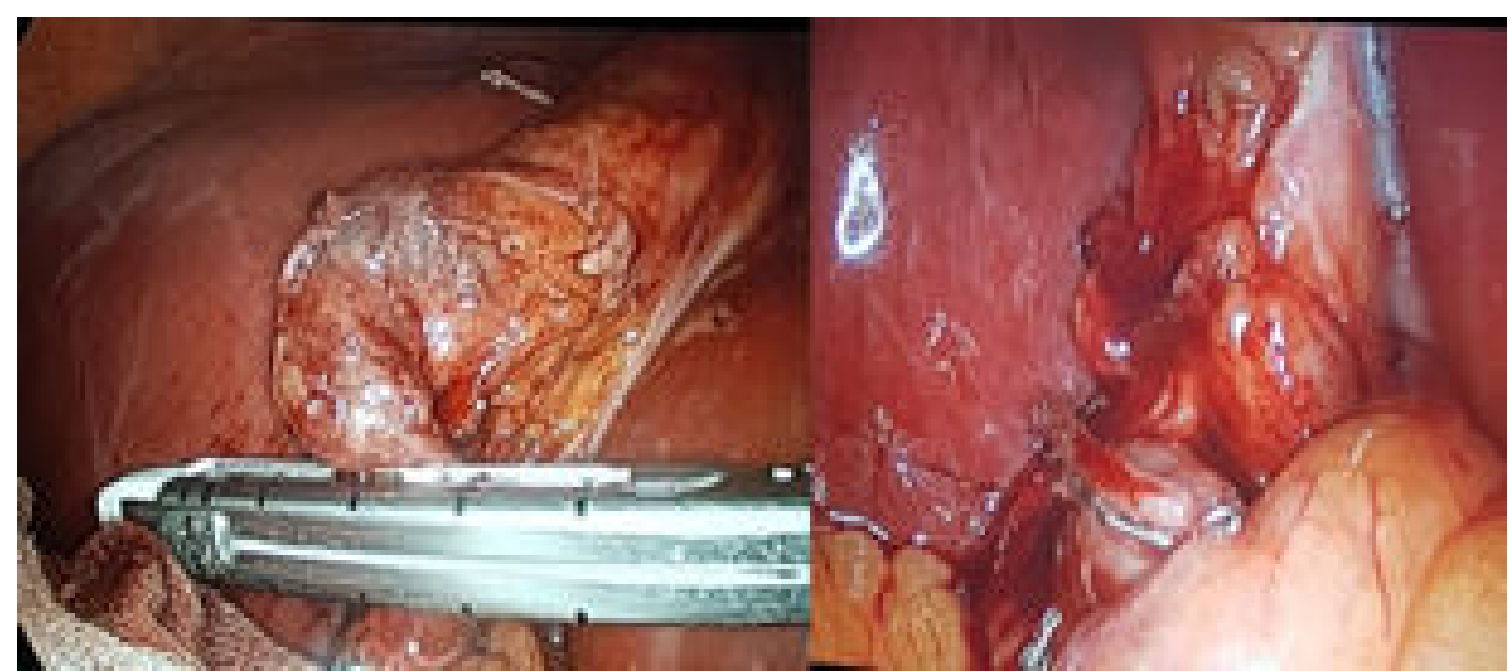

Fig. 1. Endostapler placement on large ductus cysticus and the view of the cystic stump after firing. 
in the lumen (Fig. 1).

Technically in the operation, in order to protect the main biliary tract, the gallbladder was first released from the liver bed or the hepatobiliary anatomy was revealed by reducing the gallbladder from the fundus to the Hartmann pouch. The cystic artery was seen in all patients and was cut with a titanium clip or ligasure. The gallbladder was excised from the liver bed using electrocautery and ligasure, and hemostasis was achieved.

Hemostatic matrix application was required in 3 cases for bleeding from the liver bed $\left(\right.$ Floseal $\left.{ }^{\circledR}\right)$. The gallbladder was removed from the epigastric incision outside the abdomen by taking it into the Endo-Bag inside the abdomen. Liver bed, operation area and the cystic duct stump was carefully reviewed. In all patients a soft abdomen drain extending for Winslow were placed from the 5-millimeter trocar site. The gallbladder was examined in the operating room before the operation was terminated.

\section{Statistical Analysis}

Data were analyzed with the SPSS 21 statistical program. Continuous data are given as mean \pm standard deviation where applicable, and categorical data as percentage $(\%)$.

\section{RESULTS}

Between August 2016 and December 2018, 33 patients underwent elective laparoscopic cholecystectomy in our General Surgery Clinic, and cystic canal closure was performed with 45 white loaded Endo-vasculer stapler. Nineteen $(57.6 \%)$ of the patients were males and $14(42.4 \%)$ were females. The age range was from 24 to 67 years and the median age was 48 years.

In the preoperative diagnosis of the patient group, there were $11(33.3 \%)$ patients with symptomatic gallbladder, $8(24.3 \%)$ with medically treated acute cholecystitis and 14 (42.4\%) with ERCP history (1 cholangitis, 9 biliary pancreatitis, 4 with obstructive jaundice). All patients were operated laparoscopically. In addition to these patients, 4 patients with acute cholecystitis that were diagnosed preoperatively were excluded from the study despite of using the Endostapler peroperatively. The mean hospital stay was 3.7 days. The follow-up period of the patients ranged from 2 months to 28 months.

Only one $(3.03 \%)$ patient in the study group had low flow (50 cc per day) bile leakeage in the postoperative period, and regressed totally spontaneously after 3 days. It was thought that this patient hadan aberrant bile duct (lushca) from the gallbladder bed as the cause of leakage. Three patients with wound infection were treated with antibiotics. A periumblical site hematoma was observed in one patient. No mortality was detected in the study group.

\section{DISCUSSION}

Laparoscopic cholecystectomy is the gold standard treatment for both acute cholecystitis and elective cholecystectomy [5]. Laparoscopic cholecystectomy may be a good choice for a given group after the first 72 hours after acute cholecystitis [6]. Delayed surgical treatment in patients with acute cholecystitis complicates laparoscopic cholecystectomy due to increased inflammation [7]. Early laparoscopic cholecystectomy in acute cholecystitis has been shown to be more advantageous in some publications [8-10], but in practice, patients with additional comorbidities have been given an interval because of not fulfilling the appropriate conditions. The general approach to the treatment of acute cholecystitis is not having an additional condition (associated hepatobiliary pathology choledocholithiasis, suspicion of malignancy, use of anticoagulants, etc.) and preferably laparoscopic cholecystectomy within 72 hours.However, if the patient does not have appropriate conditions for surgical intervention, a conservative approach, including cool down, antibiotherapy and minimally invasive procedures (such as percutaneous transhepatic cholecystostomy) can be applied. After 612 weeks, elective cholecystectomy should be planned $[6,11]$.

Nowadays, many techniques have been defined to prevent major biliary tract injuriesin laparoscopic cholecystectomy, but in some patients it is a problem that the cystic stump cannot be safely closed due to the large size, regardless of the technique. The biggest problem during elective laparoscopic cholecystectomy in patients with cooled down is the dissection 
difficulty of the critical calot triangle area [12]. After overcoming this difficulty and encountering a large cystic canal in the next step makes the operation even more difficult [13]. In the laparoscopic cholecystectomy operation, after revealing the Calot triangle and revealing the ductus cysticus in posterior dissection, it is essential to clearly reveal the biliary anatomy by separating the gallbladder from the liver bed [5].

The ductus cysticus is the connection between the gallbladder and the main bile duct and the diameter of this channel is known to be around 5 millimeters. When the diameter of the cystic channel increases, especially when it is above one centimeter, the laparoscopic cholecystectomy procedure becomes more difficult in acute cholecystitis and elective patients.

Multiple clips can be dangerous and may increase clip-related complications. According to Brooks et al. [14], in a series of 650 patients,laparoscopic cholecystectomy patients with 9 bile leakages were observed and three of the leakage patients were observed to be due to clip dysfunction $(0.46 \%)$. In some articles, with obstructive jaundice patients and patients with main bile duct formation examinations, it was observed that the metallic clips placed during cholecystectomy caused migration into the bile duct. Therefore, it is not recommended to put and cut multiple clips consecutively $[15,16]$. Intracorporeal knot or suture is technically difficult, requiring advanced laparoscopic experience and skill [17]. Ultrasonic coagulation and bipolar electrothermal sealers are effective in the dissection of concentrated tissues caused by hard and acute inflammation, however, this is dangerous because it might cause bile leakage [18]. Although ultrasonic coagulation was as effective as a clipin a study of the cystic canal [19], it is controversial since it will have the same security as in a wide cystic channel. An endoloop may be an alternative to the closure of a wide cystic canal but in practice, either the gallbladder is separated from the liver bed and crossed over the endo-loop pouch and seated in the cystic canal, or after the cystic channel is divided, the cystic canal can be connected to the endoloop. However, in this method, after the cystic channel is divided, it may be difficult to process as the cystic stump retracts towards the hilus [20].

The Endo-vascular stapler is used to cut and closethe cystic channel at the same time, but it is a highly debated and fearful condition in terms of overlooking main bile duct injuries. Another disadvantage is that it can only be entered through 12 $\mathrm{mm}$ diameter ports, larger than standard ports.

Endo-vascular stapling is safe and easy to use. In patients with clear cystic duct and anatomy, one must be sure that there is no stone in the cystic duct before stapler firing. It should be clearly considered that the main bile duct does not enter the stapler line and is not constricted. Before the Endo-vasculer stapler is fired, the contents of the cystic canal should be stroked by the gallbladder and the residual stone should not remain in the stapler line and should not be pushed in the direction of the main bile duct [21].

In a 7-year period (2008-2014) in France, when approximately 800,000 cholecystectomy procedures were examined, the rate of cholecystectomy due to gallbladder stones increased. When total number of cases increase, complicated cases are being expecting more frequently [22].

Although the vascular endo-vasculer stapler (2.5 $\mathrm{mm}$ ) has been preferred in most of the publications in stapled preference for cystic duct in laparoscopic cholecystectomy, staplers with reticulator $4.8 \mathrm{~mm}$ and $3.5 \mathrm{~mm}$ can be preferred [13].

The only patient with minimal bile leakage was preoperatively ERCP and sphincterotomy performed patient, bile leakage regressed spontaneously on the third day operation. ERCP applications (stent, sphincterotmy, nasobilier stent application) are effective for the management of leakage in patients with bile leak after cholecystectomy [23].

In patients that were consulted to ERCP before cholecystectomy, the surgeon feels more confident because the pressure of the bile duct decrease and leaks may heal more easily. The surgeon feels more confident with patients with a history of ERCP who underwent use of the endo-vasculer stapler for enlarged cystic channels during laparoscopic cholecystectomy.

Laparoscopic cholecystectomy is accepted as safe in elderly patients [24]. However, complication management is more difficult in these patients due to additional diseases and comorbid conditions, therefore, in the operation the surgeon should be sure of the cystic channel stump.

Although the closure of the cystic stump with 
vasculer stapler adds an additional cost on surgery, in complicated situations usage of stapler, it is obvious that it is cost-effective and should not be avoided because it might have a positive impact on decreasing postoperative complications such as biliary leakage.

The complication rate was low in our study, the complications were treatable. The duration of hospital stay was 3.7 days, which was higher than the duration of hospital stay for normal laparoscopic cholecystectomy procedures. The reason for this is the fear of developing complications. After the 10th patient, the hospital stay decreased to two days.

\section{Limitaions}

Limitaions of our study are, firstly the number of the patients in our study is low and this might affect the final results and analysis. Secondly; our study design was not prospective, retrospectively designed study. Another limitation is as the study group is a small group, there were no comparison in different groups like intra-corporeal knotting versus stapling.

\section{CONCLUSION}

In conclusion, the Endo-vasculer stapler method in elective laparoscopic cholecystectomy in complicated cases is a safe and easy method to use,especially in wide cystic duct. In the use of Endovascular stapling, it is important to note the isolation of the cystic canal and the clear presentation of the anatomy of the biliary tract.

In centers in which complicated cases undergo elective laparoscopic cholecystectomy, especially in patients with a history of stones in the main bile ductand history of ERCP, it is recommended that if a wide cystic duct is encountered while planning an operation, it may be necessary to use the Endovasculer stapler and it is recommended to be prepared preoperatively.

\section{Conflict of interest}

The authors disclosed no conflict of interest during the preparation or publication of this manuscript.

\section{Financing}

The authors disclosed that they did not receive any grant during conduction or writing of this study.

\section{REFERENCES}

1. NIH Consensus Conference. Gallstones and laparoscopiccholecystectomy. JAMA 1993;269:1018-24.

2. Muroni M, Loi V, Lionnet F, Girot R, Houry S. Prophylactic laparoscopic cholecystectomy in adult sickle cell disease patients with cholelithiasis: a prospective cohort study. Int J Surg. 2015;22:62-6.

3. Portincasa P, Di Ciaula A, de Bari O, Garruti G, Palmieri VO, Wang DQ. Management of gallstones and its related complications. Expert Rev Gastroenterol Hepatol 2016;10:93112.

4. Chowbey PK, Sharma A, Khullar R, Mann V, Baijal M, Vashistha A. Laparoscopic subtotal cholecystectomy: a reviewof 56 procedures. J Laparoendosc Adv Surg Tech A 2000;10:31-4. 5. Cushieri A, Dubois F, Mouiel J, Mouret P, Becker H, Buess G, et al. The European experience with laparoscopic cholecystectomy. Am J Surg 1991;161:385-7.

6. Koo KP, Thirlby RC. Laparoscopic cholecystectomy in acutecholecystitis: what is the optimal time for operation? Arch Surg1996;131:540-5.

7. Rattner DW, Ferguson C, Warshaw AL. Factors associatedwith successful laparoscopic cholecystectomy for acute cholecystitis. Ann Surg 1993;217:233-6.

8. Chandler CF, Lane JS, Ferguson P, Thompson JE, Ashley SW.Prospective evaluation of early versus delayed laparoscopic cholecystectomy for treatment of acute cholecystitis. Am Surg 2000;66:896-900.

9. Lai PB, Kwong KH, Leung KL, Kwok SP, Chan AC, Chung $\mathrm{SC}$, et al. Randomized trial of early versus delayed laparoscopiccholecystectomy for acute cholecystitis. Br J Surg 1998;85:764-7.

10. Lo CM, Liu CL, Lai EC, Fan ST, Wong J. Early versus delayed laparoscopic cholecystectomy for acute cholecystitis. Ann Surg 1996;223:37-42.

11. Eldar S, Sabo E, Nash E, Abrahamson J, Matter I. Laparoscopic cholecystectomy for acute cholecystitis: prospective trial. World J Surg 1997;21:540-5.

12. Kolla SB, Aggarwal S, Kumar A, Kumar R, Chumber S, Parshad R, et al. Early vs delayed laparoscopic cholecystectomy for acute cholecystitis: a prospective randomized trial. Surg Endosc 2004;18:1323-7.

13. Odabasi M, Muftuoglu MAT, Ozkan E, Eris C, Yildiz MK, Gunay E, et al. Use of stapling devices for safe cholecystectomy in acute cholecystitis. Int Surg 2014;99:571-6.

14. Brooks DC, Becker JM, Connors PJ, Carr-Locke DL. Managementof bile leaks following laparoscopic cholecystectomy. Surg Endosc 1993;7:292-5.

15. Arnaud JP, Bergamaschi R. Migration and slipping of metalclips after celioscopic cholecystectomy. Surg Laprosc Endosc 1993;3:487-8.

16. Mansvelt B, Harb J, Farkas B, Mourou M, Huguet C. "Clipstone" filiation within the biliary tract. HPB Surg 1993;6:185-8.

17. Belgaumkar AP, Carswell KA, Chang A, Patel AG. The dangers of using stapling devices for cystic duct closure inlaparoscopic cholecystectomy. Surg Laparosc Endosc 
PercutanTech 2009;19:194-7.

18. Yeh CN, Jan YY, Liu NJ, Yeh TS, Chen MF. Endo-GIA forligation of dilated cystic duct during laparoscopic cholecystectomy:an alternative, novel, and easy method. J Laparoendosc Adv Surg Technol 2004;14:153-7.

19. Ai XM, Ho LC, Yang NY, Han LL, Lu JJ, Yue X. A comparative study of ultrasonic scalpel (US) versus conventional metal clips for closure of the cystic duct in laparoscopic cholecystectomy (LC): a meta-analysis. Medicine (Baltimore) 2018;97:e13735.

20. Nowzaradan Y, Meador J, Westmoreland J. Laparoscopic management of enlarged cystic duct. Surg Laparosc Endosc 1992;2:323-6.

21. Lee MR, Chun HT, Roh YH, Kim SH, Kim YH, Cho SH, et al. Application of an Endo-GIA for ligation of the cystic duct during difficult laparoscopic cholecystectomy. Hepatogastroenterology 2011;58:285-9.

22. Bray F, Balcaen T, Baro E, Gandon A, Ficheur G, Chazard E. Increased incidence of cholecystectomy related to gallbladder disease in France: analysis of 807,307 cholecystectomy procedures over a period of seven years. J Visc Surg 2019;156:209-15.

23. Di Lascia A, Tartaglia N, Fersini A, Petruzzelli F, Ambrosi A. Endoscopy for treating minor post-cholecystectomy biliary fistula. A review of the literature. Ann Ital Chir 2018;89:270-7. 24. Mesquita ARM, Iglesias AC. Risk factors for elective laparoscopic cholecystectomy morbimortality in elderly. Rev Col Bras Cir 2018;45:e1995. 